\title{
Use of 'the mankini' for optimal exposure of the perineum
}

\author{
JLG Ma, R Islam, PN Strauss \\ Central Gippsland Health, 155 Guthridge Parade, Sale, Victoria 3850, Australia
}

Corresponding author: Joyce LG Ma (joyce.ma89@gmail.com)

Keywords: perineum; exposure; anorectal surgery; coloproctology; surgical technique

\section{Introduction:}

Adequate exposure of the perineum in anorectal surgery is essential, but can be difficult to achieve in some patients. We have devised a simple and inexpensive technique which will allow us to expose the perineal region with ease.

\section{Body of text:}

In colorectal surgery, there are many operations and procedures that require adequate exposure of the anus and

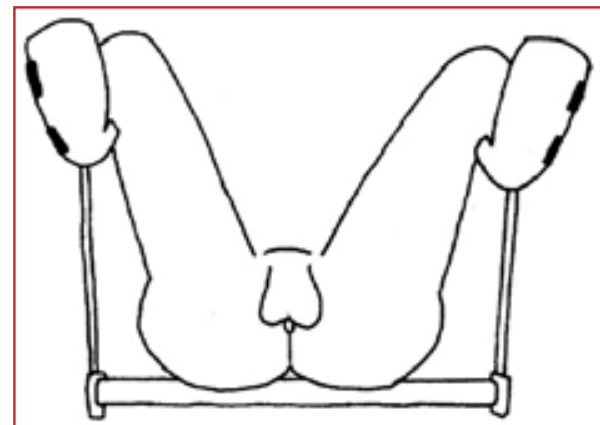

1. The patient is placed in lithotomy position.

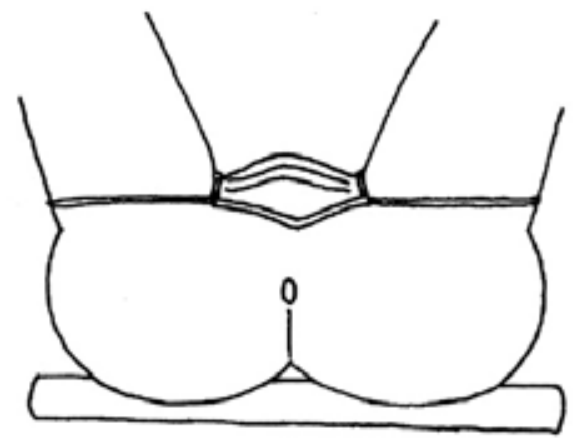

3. The mask is tied around the patient's legs which allows elevation of the genitalia.

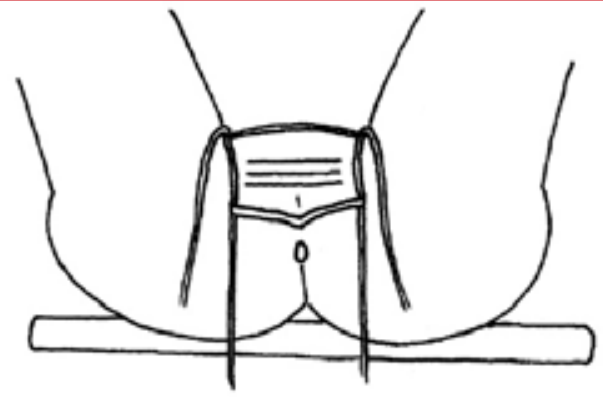

2. Surgical mask is placed with nose wire facing downwards so that the wire can be moulded to support the scrotum.

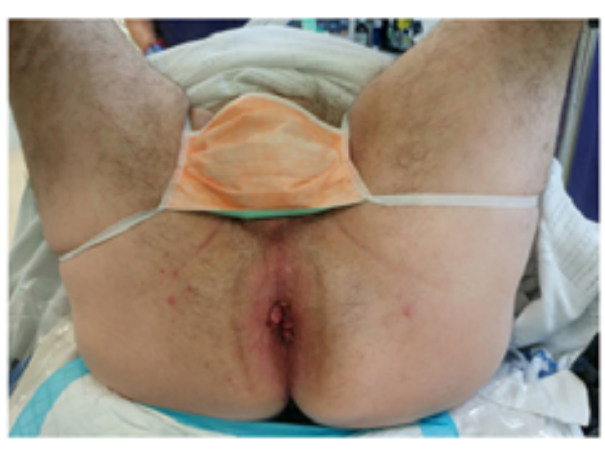

4. Use of the mankini on a patient about to undergo an anterior resection.

Figure 1. Application of the mankini

perineum. In some patients, particularly male patients, it may be difficult to achieve this due to a low-lying scrotum.

Here, we describe the technique of using a surgical face mask to elevate the scrotum for optimal exposure. This technique is named 'the mankini'. The patient is placed in lithotomy position. A surgical face mask is placed over the patient's genitalia, with the nose wire facing downwards so that it can be moulded to support the scrotum. The ties are then tied around the patient's legs so that the patient's genitalia are elevated away from the anus and perineum. At this point, the perineum is well exposed, and the patient can be prepped and draped for the procedure. The illustrations and photograph demonstrate the use of the mankini on a patient about to undergo an anterior resection (Figure 1).

We have used the mankini technique in numerous patients. It is easy to apply, cost-effective, and provides optimal exposure of the perineum while maintaining sterility of the operative area. There are no reported complications from the use of the mankini.

\section{Conclusion:}

The mankini is a safe and effective method for optimal exposure of the perineum. We recommend the routine use of the mankini on all male patients undergoing procedures that require exposure of the anus and perineum.

\section{References}

None. 